Revue internationale de l'économie sociale

Recma

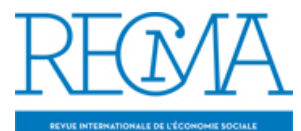

\title{
À la mémoire de Jean-Yves Manoa
}

\section{Serge Koulytchizky}

Numéro 286, novembre 2002

URI : https://id.erudit.org/iderudit/1022233ar

DOI : https://doi.org/10.7202/1022233ar

Aller au sommaire du numéro

Éditeur(s)

Institut de l'économie sociale (IES)

ISSN

1626-1682 (imprimé)

2261-2599 (numérique)

Découvrir la revue

Citer ce document

Koulytchizky, S. (2002). À la mémoire de Jean-Yves Manoa. Revue internationale de l'économie sociale, (286), 5-5. https://doi.org/10.7202/1022233ar d'utilisation que vous pouvez consulter en ligne.

https://apropos.erudit.org/fr/usagers/politique-dutilisation/ 


\section{À LA MÉMOIRE DE JEAN-YVES MANOA}

A

u premier abord, une austérité de mise, une allure de clergyman mais éclairée souvent 1 l'architecture serrée de l'argumentation... ainsi était Jean-Yves Manoa. Peu disert avec ses pairs, paraissant cultiver une part de mystère, il était sans doute assez timide, réservé, de la réserve de ceux qui n'ont pas abordé directement aux rives de l'Université parce qu'ils ont connu un premier métier qui donne une vraie profondeur à la pratique enseignante. Claude Vienney et Lionel Monnier appartiennent tous deux à cette même veine. Le premier, Claude Vienney, a ouvert à Jean-Yves Manoa, à l'université de Paris-I, les portes de l'enseignement dans le cadre d'un cours sur "L'économie sociale: organisations et marché interne ". S'ensuivront, pour l'économiste qu'il était, huit années d'un DESup pour adultes. En même temps il intervenait déjà, recruté par Albert Pasquier, dans le DESS de l'université du Maine, à l'époque seul de sa catégorie "économie sociale " en France.

Après l'arrêt du DESup parisien, nous avons réussi à lui confier au Mans, en service officiel, un cours annuel spécialisé de vingt-cinq heures; tout le reste, à Paris (AES), était devenu hors champ de l'économie sociale. Au Mans, nous avions alors à quelques-uns de vibrantes discussions de recherches, dans la crêperie habituelle proche de la faculté. Mêmes amicales controverses ici et là, un peu plus loin cette fois, dans le cadre du Centre international de recherches et d'information sur l'économie publique, sociale et coopérative (Ciriec). En effet, Lionel Monnier avait accueilli Jean-Yves Manoa au sein du conseil scientifique et international qu'il présidait alors au Ciriec.

Jean-Yves Manoa a participé à deux groupes de travail, l'un sur les « holdings coopératifs » dont il était membre du comité éditorial, l'autre sur la "structure de gouvernance ", qui n'a pas achevé ses travaux et qui, en son absence, reste malheureusement en panne de francophonie. Dernières réunions communes à Liège et en Suède, à Gavle (2001); et pour Lionel Monnier, souvenir d'une mission commune en Turquie à Ankara (4 juin 2001). Ensuite plus rien... et surtout plus rien après la disparition de Claude Vienney, le 12 juillet 2001.

Le 5 juillet 2002, Jean-Yves Manoa décède à l'âge de 56 ans.

Sans faire nécessairement référence à la coïncidence des dates, l'hommage que nous rendons ici s'adresse à Jean-Yves Manoa, "Ardéchois cœur fidèle ", ouvrage ${ }^{(1)}$ sous l'égide duquel s'était placé notre premier compagnonnage, en Russie, à Moscou, en 1995. Ardéchois, Jean-Yves l'était et l'était bien.

(1) Jean Chatenet, Jean Cosmos, Ardéchois cœur fidèle, l'aventure du compagnonnage, Ed. Claude Lattès, Paris, 1974. 